\title{
CORPO, TEMA E O ESPAÇO DA SALA DE AULA
}

Hélio Junior Rocha de Lima ${ }^{\mathrm{i}}$

\begin{abstract}
Resumo: Esta pesquisa visa instigar reflexões sobre experiências no âmbito da sala de aula, nos estudos e dinâmicas do componente curricular corpo, movimento e ludicidade do curso de Pedagogia. Considerando o caráter intersubjetivo do tema, o professor pesquisador tece observações sobre o desdobramento das aulas com alusão aos estudos introdutórios teóricopráticos do teatro-imagem, proposto por Augusto Boal, e dos movimentos cotidianos e espontâneos elucidados por Rudolf von Laban atravessados por abordagens sobre o tema nos estudos de Paulo Freire, Nickel, Marques e Lima. Verifica-se que a discussão do corpo e movimento, como ação, como atitude no cotidiano, faz emergir questões reveladoras de conhecimento e negação da linguagem corporal em tempos de distanciamento social.
\end{abstract}

Palavras-chave: Corpo e movimento; Dança educativa; Jogo teatral; Teatro-imagem.

\section{BODY, THEME AND CLASSROOM SPACE}

\begin{abstract}
This research aims to instigate reflections on classroom experiences concerning body language, movement and playfulness. Considering the intersubjective character, the research professor makes observations about the unfolding of the classes of the curricular component "Body, movement and playfulness", alluding to the theoretical-practical introductory studies of the image theater, proposed by Augusto Boal, and the elucidated everyday and spontaneous movements. by Rudolf von Laban crossed by approaches on the subject in the studies of Paulo Freire, Nickel, Marques and Lima. It is verified that the discussion of body and movement, as action, as attitude in daily life, reveals questions revealing knowledge and denial of body language in times of social distance.
\end{abstract}

Keywords: Body and movement; Educational dance; Image theater; Theater game.

\section{A sala de aula e as inquietações iniciais}

São muitas dúvidas e questões que surgem na sala de aula do componente curricular Corpo, movimento e ludicidade do curso de Pedagogia. Primeiro, no tangente à prática docente na Educação Infantil e nos Anos Iniciais de Ensino Fundamental, inquietações acerca das competências do professor recaem sobre a formação em Pedagogia, uma vez que as ações propostas implicam conhecimentos tanto das Artes como da Educação Física; segundo, se o corpo, o movimento e a ludicidade compõem a didática do professor, como o pedagogo dos Anos Iniciais do Ensino Fundamental procederá com os recursos didáticos dessa natureza sem avançar as fronteiras da área? 
O programa geral do componente curricular - Corpo, movimento e ludicidade -, tem seus objetivos direcionados para a formação de professores que atuarão na Educação Infantil e no Ensino Fundamental, de modo que apresenta entre a visão biopsicossocial do corpo, o caráter da experiência em que as interações acontecem no reconhecimento espacial, nas descobertas individuais e coletivas, em diferentes concepções alternativas metodológicas dos jogos e brincadeiras. A ênfase se dá na vivência do jogo pelo professor, pois entende-se que, ao experienciar o jogo e a brincadeira, o professor entenderá os objetivos, os sentidos e habilidades corporais excitados. O professor não conhecerá o jogo apenas na sua descrição, ele também ativará seu estado lúdico, necessário à motivação dos alunos durante a coordenação dos jogos.

Como ação reflexiva do componente curricular - Corpo, movimento e ludicidade -, a pesquisa se pautou em verificar as questões dos estudantes durante as aulas, a abordagem selecionada para introduzir o tema, neste caso, dando relevo às concepções históricas e sociais do corpo; às dinâmicas de escolhas temáticas nos movimentos espontâneos e improvisacionais em Rudolf von Laban ${ }^{\mathrm{ii}}$ e Augusto Boaliii; dentre outras práticas educativas criadoras, cuja abrangência abarca os jogos e as brincadeiras na Educação Infantil, observando nessas práticas a ética, a política, e as construções democráticas e afetivas.

Concentramos no tema e nas metodologias em sala de aula com os movimentos em Laban e Boal, por entendermos que, nesses sistemas, o tema exerce uma função fundamental para o acontecimento dos movimentos corporais, das expressões dançadas ou por meio do teatro imagem. E no decorrer das reflexões das ações, a pesquisa se move no contexto pandêmico da COVID-19, no qual o espaço e os procedimentos se encontram em fase laboral, experimental, de tentativas de fazer acontecer a prática de ensino no ambiente virtual. Neste caso, o componente curricular, diante da situação de aulas à distância, apresenta muitos desafios, que não deixarão de ser ressaltados ao longo do texto.

\section{Um corpo sem ação, docilizado}

O corpo é organismo expressivo de linguagem própria e recaem, sobre ele, exigências, estilos e condutas corporais que representam cada grupo cultural e social. Ao que parece, o ensino com abordagens tradicionais acentua no corpo feitios que estão de acordo com os padrões aceitáveis, ou seja, enfatiza-se um corpo educado, docilizado. Entretanto, de tal modo, reafirma-se a necessidade de estudos das concepções e abordagens na Educação que Revista Interinstitucional Artes de Educar. Rio de Janeiro, V. 7, N. 1 - pág. 447-466 janeiroabril de 2021: "Pedagogias Vitais: Corpo, Desejo e Educação" DOI: 10.12957/riae.2021.54952 
promovam outras formas sensíveis de diálogos em sala de aula, além de uma tendência tradicional de ensino. O que se pretende, no entanto, é trazer à tona questionamentos acerca da formação de pedagogos. Como compreender a dimensão educativa da matéria sem o experimento do corpo em situações espontâneas? No ato do ensino e da aprendizagem, das leituras e percepções corporais, quem aprende e quem ensina? O jogo, a brincadeira, parte do professor como mera aula planejada? Ou o professor também é o brincante? A brincadeira, o estado lúdico, seria um atributo apenas das crianças? Qual o papel do professor no jogo?

Qual a importância do componente curricular Corpo, movimento e ludicidade na graduação de formação de professores pedagogos? Paulo Medina ${ }^{\text {iv }}$ (1987), em Corpo $e$ sociedade brasileira: as condições concretas da corporeidade, traz a historicidade da corporeidade da nossa realidade brasileira. Ao pensarmos o Brasil, nos damos conta da realidade, na maneira de vestir e de cultuar o corpo. O autor afirma que:

Somos a todo tempo requisitados a ser filhos obedientes, pais trabalhadores e responsáveis, professores que ensinem o óbvio-padrão, mães dedicadas, amantes fiéis, cidadãos pacíficos e cumpridores de nossas obrigações, mulheres sensuais, dóceis ou submissas, militares respeitadores da ordem estabelecida, alunos estudiosos (pouco importando se o conteúdo de ensino nos interessa ou não) [...]. (MEDINA, 1987, p.81)

Na relação corpo e sociedade, vê-se a delimitação de valores e moralidades. No âmbito educacional parece não ser diferente, todos são levados a seguir as regras preestabelecidas. Um jogo social em que a negação desses valores se traduz em perturbações da ordem não é aceito e logo visto como indisciplina. Na escola, a reprodução dos comportamentos docilizados e a ideia de que criança quieta é criança "bem educada" se mantém como um caminho de controle da educação. São orientações que vão desde as cores para meninos e meninas, das vestimentas, às que delimitam movimentos corporais. A manifestação fora do padrão gera estranhamento, desconforto, e a exclusão das pessoas tidas como diferentes. Não se adequar às convenções sociais dificulta as relações interpessoais e causa distanciamentos. É uma lacuna fértil que potencializa um ciclo vicioso de opressão, com relevos de bullyings e vidas associais.

Quando pensamos o corpo, quando atuamos na vida, não há como disfarçar sentimentos, modos rígidos de atuar no mundo ou espontaneidade. O corpo é presença, é ocupação no espaço. As ações das pessoas, as transformações sociais, as mudanças que provocamos nos espaços e mesmo nos grupos sociais, são acontecimentos que implicam ações, atitudes, movimentos. Ou seja, tudo acontece no corpo. 
Uma visão liberal do ensino, assim como tece Libânio ${ }^{v}$ (1992), ou uma prática bancária como nos disse Paulo Freire ${ }^{\mathrm{vi}}$ (1993), reforça uma ideia vertical de ensino, tendência pedagógica diretiva, de controle, cujo objetivo é moldar pessoas aos interesses sociais, de formar trabalhadores, mão de obra e de pacificar os ânimos, docilizar como sinônimo de educar. Nessas abordagens diretivas preza-se por alunos sentados, quietos e calados, como se a aprendizagem só fosse possível com crianças “comportadas". Medina (1987) frisa a responsabilidade de cada cidadão em conhecer seus direitos para melhoria do padrão de vida e de perceber que nossas liberdades estão determinadas pelos limites impostos pela sociedade. “Contra esses limites é necessário lutar coletivamente" (MEDINA, 1987). Essa luta coletiva começa no espaço da sala de aula e dos acordos, das escolhas, do diálogo.

Romero $^{\text {vii }}(2005$, p. 58) afirma que: “O corpo dócil, obediente e disciplinado é o resultado de uma conjugação de forças, com atenção dedicada ao corpo com o propósito de manipulá-lo e treinar para obedecer, enfim, um corpo docilizado." Este corpo dócil é também uma recorrência nas escolas, à medida que as imposições de regras aos alunos, como já foi ressaltado é o direcionamento dado. Há uma tentativa de manter os alunos parados e quietos. Para melhor compreensão desta discussão a autora diz que: "De maneira mais sutil, o corpo do aluno é disciplinado. Nos colégios, as minúcias dos regulamentos a serem cumpridos denotam a existência de uma política de submissão altamente codificada em rituais de obediência" (ROMERO, 2005, p. 57-58). Não é somente a mera prática de manter os alunos sentados e quietos, a autora deixa claro que existem várias práticas "minuciosas" que acontecem até mesmo sem percebermos, que fazem com que se construa paulatinamente a ideia de aluno disciplinado.

Fazendo o contrafluxo à lógica de uma educação bancária, desejamos criar um ambiente que desconstrua a hierarquia do espaço e nas relações alunos-alunos, professoralunos, alunos-professor. Percepção do espaço individual, e da percepção do corpo na interação com os outros, com o coletivo. Partilhas sensíveis de ocupação e facilitação para o outro. O movimento cotidiano de interação, experimentação do espaço dos movimentos corporais que se atravessam. O corpo vem primeiro, chega no espaço, preenche o espaço, interage com os outros. O espaço, dependendo de como ele recebe o corpo, e de como esse corpo atua nele, pode proporcionar um estado lúdico, brincante, esperado como o estado de extrema necessidade para o jogo.

Vinicius Santin viii (2005, p. 310) ao discutir sobre o corpo lúdico, afirma que: "a visão lúdica do corpo significa a visão que temos do corpo ou a visão que o corpo apresenta". Ou seja, tanto podemos compreender o corpo lúdico ou a maneira como o corpo pode ser lúdico. Revista Interinstitucional Artes de Educar. Rio de Janeiro, V. 7, N. 1 - pág. 447-466 janeiroabril de 2021: "Pedagogias Vitais: Corpo, Desejo e Educação" DOI: 10.12957/riae.2021.54952 
O autor acredita que, na brincadeira, o corpo lúdico é uma vivência, um momento, uma ação, um agir. Isto é, o lúdico é o que cria, imagina, inventa, faz de conta, se envolve. Facilitar o jogo, animar a brincadeira, envolver-se na vivência auxilia o professor a conhecer o jogo por dentro, experienciando e conhecendo sua importância, os sentidos exercitados, função e objetivos na ação pedagógica. O professor, ao atuar como instigador, promove uma relação horizontal e dialógica.

A sala de aula entendida como ambiente de acontecimentos reivindica ressignificações e transformações. A preparação do ambiente para o jogo sugere novas descobertas, novas observações, refazimentos do ambiente, rever, descobrir outras possibilidades de exploração e de ocupação. A sala de aula transforma-se num laboratório, num espaço de pesquisas corporais, dramáticas. Espaço de novos encontros. Espaço de estudo e de pesquisa. Os corpos que nela habitam são atravessados pela história, portanto singulares e diversos. Aqui cabe também pensar o corpo na sua abrangência, ultrapassando, sobretudo, as barreiras etárias.

Há uma tendência, quando se pensa para o curso de formação de professores do Ensino Fundamental, de uma discussão estanque do corpo, distante, separada, como se o processo de formação se limitasse apenas aos temas que tratam do corpo da criança que está "lá" no espaço escolar ou não escolar, e quase nunca de um corpo adulto que está aqui e agora e que se prepara para encontrar o corpo-criança em desenvolvimento. Outro aspecto que merece atenção nesta experiência é o de que as atividades se dão no curso de formação de professores pedagogos e não na formação específica da área da Dança, do Teatro ou da Educação Física. No entanto, os jogos corporais espontâneos e temáticos fluem nas propostas do professor, atravessando o planejamento das aulas e indo além da mera reprodução das indicações dos jogos pelo professor, mas corroborando e dinamizando as relações intersubjetivas no espaço educativo onde a ação anima as possibilidades temáticas que emergem nas dinâmicas espontâneas dos professorandos. Para $\operatorname{Scarpato}^{\mathrm{ix}}$ (1999, p. 53), “ $O$ professor precisa compreender a importância do movimento no processo de ensinoaprendizagem e propiciar essa oportunidade ao aluno, deixando fluir o Método Natural e a livre expressão". E aqui acrescentamos, que o professor não apenas propicie aos alunos, mas a ele próprio a jogar.

Adentrar no jogo e participar intensamente da brincadeira são inquietações que emergiram em meio às aulas de corpo e movimento. Em diversos depoimentos, as estudantes de Pedagogia trouxeram assuntos sobre a participação do adulto nas brincadeiras infantis. Indaga-se a falta de intensidade do adulto no jogo demonstrando desinteresse e, às vezes, participando apenas como aquele que descreve o jogo, porém não joga. Para as estudantes do Revista Interinstitucional Artes de Educar. Rio de Janeiro, V. 7, N. 1 - pág. 447-466 janeiroabril de 2021: "Pedagogias Vitais: Corpo, Desejo e Educação" DOI: 10.12957/riae.2021.54952 
componente curricular, a participação efetiva do professor ou do adulto no jogo, vivenciar intensamente a brincadeira com a criança, potencializa as funções do jogo, seus aspectos pedagógicos e comunicativos. Ao contrário, o jogo como obrigação do adulto, para cumprir um protocolo ou, mais intrigante ainda, "fazer de conta" que está participando da brincadeira, é extremamente desinteressante e até tedioso.

Nas dinâmicas nada parece tão instigante do que mergulhar na brincadeira de corpo inteiro, com vontade. A criança percebe quando a brincadeira do adulto não é verdadeira. Nesse mundo digital, tecnológico, televisivo, os pais têm pouco tempo para brincar. Os meios de comunicação desviam a atenção e o jogo precisa de foco. Já há professores que, ou estão preocupados em cumprir com o planejamento, os conteúdos curriculares, ou não lhes sobram tempo para se concentrarem em ações espontâneas com a turma. Falta de tempo, dificuldade de concentração na atividade lúdica ou medo de perder a "autoridade", portanto o "domínio" da sala de aula? Essas são questões que se juntam às demais supracitadas. Esse temor apareceu, principalmente, em salas de aula do terceiro ao quinto ano. A indisciplina parece provocar no professor certo distanciamento.

Ser mais um brincante, fazer parte do jogo, é um estágio almejado por aqueles que não se orientam por uma proposta conservadora, diretiva de educação. Embora a expectativa de atender a seus anseios, sem ser coaptado pela liturgia de um ensino bancário, leve o professor a recorrer a dispositivos no qual ele próprio luta para transpor, o desejo e a ação de jogar intensamente implica uma atuação interativa, participativa da turma. O controle se dá com base nas regras do jogo acordadas com os alunos.

Sendo o corpo um objeto que sente e interage com o mundo (NISTA-PICOLLO; MOREIRA, 2012) o conhecimento e mesmo o reconhecimento dele eleva-se com uma constância necessária no processo ensino-aprendizagem, tanto para o professor como para o aluno. Além disso, libertar o corpo da condição de objeto, agir para que ele rompa com as barreiras da docilidade, parece-nos um desafio para uma educação libertadora.

O corpo enquanto objeto é passivo, reprodutor de comportamentos e determinações sociais, ou ocupa espaço em seu estado sem vida, morto. Quando Nista-Picollo e Moreira ${ }^{\mathrm{x}}$ (2012, p. 72) cita Gardner (1997), se refere à brincadeira como uma operação indisciplinada na qual as crianças experimentam "comportamentos, ações e percepções sem medo de represálias ou fracassos". Nesse sentido, queremos crer que o corpo exercita atos libertadores da condição de objeto. A presença, percepção espacial, o movimento individual e coletivo, cuidado de si e do outro, os sentidos, as sensações em jogo potencializam singularidades e o 
entusiasmo possível de um corpo permanentemente ativo, expressivo, que faz uso de outras potencialidades comunicativas.

Transcorrem, neste artigo, dois momentos de estudos e práticas com as estudantes do componente curricular Corpo, movimento e ludicidade, que aconteceu por meio do ensaio de atividades na sala de aula em caráter presencial e à distância com fluência metodológica do teatro-imagem e da dança educativa.

Para quem são os jogos e dinâmicas desenvolvidas na sala de aula do curso de formação de professores? Esta é uma questão intrigante. Uma vez solicitado aos graduandos que descrevam o que esperam do componente curricular Corpo, movimento e ludicidade, observa-se que, entre as questões levantadas, é recorrente a necessidade de terem um arsenal de jogos para proporem quando estiverem exercendo a função de professores, ou seja, um repertório de dinâmicas corporais, de jogos dramáticos que os auxiliem na sala de aula. Ao que parece, tal necessidade não é totalmente dispensável. Um repertório poderá contribuir com o trabalho do professor, porém exigirá reorientações desses jogos implicadas na realidade do grupo e nas novidades dos acontecimentos e intersubjetividades dos alunos. Por outro lado, mais do que um adulto como orientador das dinâmicas corporais, o experimento de jogos e brincadeiras no campo da expressão corporal, pelos adultos, possibilita a compreensão e valorização de uma prática vivenciada.

Nas competências gerais da Base Nacional Comum Curricular da Educação Básica, o corpo, gestos e movimentos compõem as competências gerais, embora ainda trate de maneira aligeirada dos direitos de aprendizagem e desenvolvimento na Educação Infantil, tendo em vista os eixos estruturantes da Educação Básica: conviver, brincar, participar, explorar, expressar e conhecer-se em jogo, que requer o desprendimento do adulto para o reconhecimento em si da importância de tais direitos para o exercício dos sentidos e afetos da pessoa. Como defender tais direitos num processo educativo se não se tem o desprendimento de vivenciar tais direitos? Como promover momentos lúdicos em sala de aula de forma sisuda, dura, circunspecta na aplicação de um currículo inflexível, fechado às novidades?

Brincar cotidianamente de diversas formas, em diferentes espaços e tempos, com diferentes parceiros (crianças e adultos), ampliando e diversificando seu acesso a produções culturais, seus conhecimentos, sua imaginação, sua criatividade, suas experiências emocionais, corporais, sensoriais, expressivas, cognitivas, sociais e relacionais. (BNCC, 2017, p. 36) 
Em $O$ jogo e a criança, Jean Chateauxi (1954) faz a pergunta: "Por que as crianças brincam?" Aqui, a pergunta se volta para o professor: por que adultos não brincam? Ou, por que adultos precisam reaprender a brincar?

Acredita-se que a experiência do jogo aguça a percepção do professor sobre o potencial do brincante em reinventar-se no jogo, em trazer para o ato expressivo o seu tempo, seus conhecimentos de mundo, suas leituras, sobretudo, ressignificações que, por vezes, desviam das regras iniciais, recompondo direções. Essa perspectiva não relega as metodologias com seus traços delimitados de ações no jogo, mas flexibiliza possíveis acontecimentos no sentido do estado espontâneo que impulsiona o jogo. Decerto, a viabilidade da improvisação amplia a experiência do jogador em novas descobertas expressivas e motiva-o para jogos com regras mais desafiadoras.

[...] a instituição escolar precisa promover oportunidades ricas para que as crianças possam, sempre animadas pelo espírito lúdico e na interação com seus pares, explorar e vivenciar um amplo repertório de movimentos, gestos, olhares, sons e mímicas com o corpo, para descobrir variados modos de ocupação e uso do espaço com o corpo (tais como sentar com apoio, rastejar, engatinhar, escorregar, caminhar apoiando-se em berços, mesas e cordas, saltar, escalar, equilibrar-se, correr, dar cambalhotas, alongar-se etc.(BNCC, 2017, p. 38-39)

Após os jogos de caráter espontâneo, não espontaneísta, ainda que regidos sob regras básicas, a improvisação faz surgir temáticas livres revistas nas atividades seguintes. As relações intersubjetivas em sala de aula dadas no acontecimento individual e coletivo de movimentos inspirados na dança educação, mais precisamente nos oito temas de movimento básico e fatores de esforço de Rudolf von Laban, mesmo não seguindo o método em sua abrangência, as indicações de que todo movimento no cotidiano implica em tempo, espaço, fluência e peso, dava a partida para introduzir no movimento da dança aqueles realizados no cotidiano, como: pular, correr, empurrar, girar etc. Deste modo, os professorandos fluíam na dança compondo sequências de movimentos.

\section{O ambiente virtual, a sala de aula em casa e proposições}

Diante da pandemia que assola o mundo e da emergente necessidade de distanciamento social, este tópico foi introduzido posteriormente neste artigo. Pareceu quase impossível pensar as atividades com jogos dramáticos e movimentos improvisacionais cujos Revista Interinstitucional Artes de Educar. Rio de Janeiro, V. 7, N. 1 - pág. 447-466 janeiroabril de 2021: "Pedagogias Vitais: Corpo, Desejo e Educação" DOI: 10.12957/riae.2021.54952 


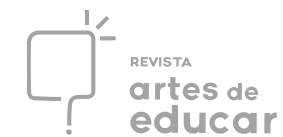

princípios implicam no estabelecimento relacional, espacial, do encontro de pessoas que desafiam seus corpos em movimentos expressivos, de fisicalidades, representações e performances remotas do ensino. Abstrações nos entrelaçados coletivos de corpos, nos desafios dos movimentos corporais, nos sentidos do movimento individual e coletivo exigem o tempo e espaço para que sejam explorados. A experimentação por parte dos professorandos, ao que tudo indica, fica ameaçada, atenuada, menos viva.

A princípio, com o distanciamento social, com o primeiro óbito por coronavírus no âmbito local, oriundo do corpo docente da universidade, repentinamente fomos atravessados pelo acontecimento, o plano de trabalho sofreu grandes abalos. Uma vez que no componente curricular além dos estudos, das leituras ao longo do semestre, ficou impossível de realizar, em caráter presencial, os experimentos com jogos em sala de aula e as atividades corporais coletivas que exploram e ocupam outros espaços.

Todavia, emerge a necessidade de releituras e de novos enfrentamentos com as proposições e práticas de ensino. O impacto maior, longe de uma discussão acerca da Educação à Distância - EaD, assunto que foge aos nossos propósitos neste trabalho, são com as palavras "remoto" e "distância". Evidentemente, estamos frente a um acontecimento nos exigindo outro modo de perceber os processos de aprendizagens, sucumbindo modos de pensar o currículo participativo, dinâmico, afetivo, crítico, subjetivo, dialógico, modos pelos quais a presença corporal se faz necessária, atuante, motivadora. Mesmo lidando com a virtualidade, com o universo da leitura de livros, o embate, o encontro corporal potencializa nossas buscas presenciais. Um ensino distanciado, a meu ver, sempre teve um sabor de tradição, conservação na trincheira do ensino bancário. Tais indagações se apresentam como os primeiros desafios para repensar o ensino à distância no tocante à metodologia, à dinâmica da sala de aula, além de enfrentar problemas econômicos, técnicos e de acessibilidade. $\mathrm{O}$ Planejamento se deu em meio às políticas institucionais, apoio técnico e cursos de capacitação para atuar no ambiente virtual.

Nesse contexto, pensamos para o planejamento uma unidade de práticas de leituras e pesquisas para introduzir conteúdos e instigar o diálogo, como já mencionado nos tópicos anteriores, abordando a construção cultural do corpo humano, concepções através dos tempos, conceito de ludicidade, e, na unidade seguinte, vislumbramos práticas educativas com o intuito de verificar se os jogos e brincadeiras, como também movimentos de dança e teatro podem ser realizados à distância e quais objetivos e habilidades indicam alguns objetivos de aprendizagens que estivessem de acordo com aqueles das aulas presenciais. 
Construções propositivas para dinamizar o corpo, movimento e ludicidade no ambiente virtual da sala de aula em casa tornam a sala virtual um laboratório de experimentos e tentativas metodológicas de ensino. Proposições para aprimorar a didática do professor em situações adversas que exigem distanciamento de alunos e professores. Ao que nos apontam as reflexões até o momento realizadas, reencontrar a sala de aula no espaço de casa, da escolha do lugar, e a promoção do trabalho atento, a concentração e interação com os demais, parecem ser pontos cruciais; outro ponto crível é a seleção e criação de dinâmicas individuais: solos, leituras dramáticas, exercícios e jogos.

Os grupos formados em sala de aula para realizar as leituras e tarefas continuam no ambiente virtual. A maneira que o grupo busca o tema vai, desde as improvisações aleatórias e a seleção dos assuntos recorrentes, às demarcações temáticas com referência ao texto lido ou as indicações externas de um projeto cujo interesse temático conduz as criações.

\section{O tema, perspectivas e possibilidades}

O tema, quando pensado em primeira mão, causa a impressão, tão logo, de que é um vetor que orienta, encaminha o pensamento e as ações para um determinado lugar; ao seguirmos, organizamos um leque de procedimentos evitando desvios acentuados no percurso. $\mathrm{O}$ tema leva às referências objetivas que se julgam como necessárias ao alcance do entendimento do que se quer realmente. Ou seja, o tema lança em campo variações e delimitações das ações. Do grego Thêma que significa o que é proposto, o assunto, o tema é o ponto provocador de debates.

No livro $O$ inconsciente estético, no primeiro capítulo, Jacques Rancière ${ }^{\text {xii }}$ (2009) inicia falando do defeito de um tema. Atentamos ao título no original do livro em língua francesa que é Le défaut d'um sujet. A tradutora, Mônica Netto, traz uma nota curiosa, quando diz que há ambiguidade na tradução de sujet, por também significar assunto, objeto, argumento, tema. Defeito de um tema, que também se pode chamar de defeito de um sujeito, é a análise que Rancière faz da tragédia encomendada ao dramaturgo francês Pierre Corneille, comentando sobre a adaptação do Édipo de Sófocles. Ora, foi encomendada uma tragédia, e como autor de tragédia Corneille decide reescrever o Édipo, de Sófocles, e ao fazê-lo percebe a armadilha. Não se tratava de fazer apenas uma transposição para língua francesa, mas de remodelar, de adaptar e fazer algumas supressões de cenas. Neste caso, para realizar o produto dramático encomendado, o dramaturgo parte de outro texto teatral. Debruça-se no Revista Interinstitucional Artes de Educar. Rio de Janeiro, V. 7, N. 1 - pág. 447-466 janeiroabril de 2021: "Pedagogias Vitais: Corpo, Desejo e Educação" DOI: 10.12957/riae.2021.54952 
processo de identificar e recriar o tema de Édipo. Neste caso, o tema vem como problema e é o trabalho do autor que o reorienta.

Porém, quando se trata de uma escritura corporal, espontânea do teatro e da dança, por exemplo, os jogadores de início perguntam se a atividade terá um tema. Segundo Lima (2011), são buscas que mais parecem a busca por um porto seguro, um desejo por algo como um decreto. Seja uma "busca por um assunto, temas de movimento, ou uma criação cênica, uma estátua ou uma mímica." "O que é um tema, afinal?".

O tema é a ideia central da obra, são os elementos do conteúdo, as imagens e o leitmotiv ${ }^{\text {xiv }}$. Pavis $(2007$, p. 399) também nos apresenta pontos de vistas intrínsecos nos termos proferidos por diferentes autores, como por exemplo: —Rede organizada de obsessões (BARTHES), —arquétipo involuntárioll (DELEUZE), -imagem obsessiva traumática (WEBER). (LIMA, 2011, p. 50)

Stanislavski ${ }^{\mathrm{xv}}$ (1996) fortalece o foco no superobjetivo para orientação dos atores, como proferiu certa vez. O tema vem tanto de uma obra literária como pode ser resultante de jogos dramáticos que arrefece a busca, ou seja, tanto emerge do movimento criativo, espontâneo, sem intenção a priori, de expressividade livre de demarcação temática, como da fricção do jogo, nasce o tema. Por conseguinte, na sequência, se escolhe o texto dramático com temática relacionada ao interesse do grupo. Em geral há uma gama de leituras de textos dramáticos, contos, poesias, notícias de jornais, composição de roteiro, canevas. "Sendo o tema um esquema mais ou menos consciente e obsessivo do texto, cabe ao crítico rastrear essas estruturas temáticas, mas também decidir por meio de que temas a obra é mais facilmente explicável ou produtiva ${ }^{x v i}$ " (PAVIS, 2007 apud LIMA, 2011, p. 50).

Um tema pode definir preceitos concisamente. Vem à tona de maneira improvisada e, persistentemente, ganha formato de texto. Para Nickel ${ }^{\text {xvii }}$ (2009), pensar o tema antes de iniciar os jogos teatrais é um caminho trilhado por alguns grupos. Lima (2011) diz que o tema submerso pode ser fisgado no texto dramático pelo encenador. Esse tema que não se apresenta diretamente, que não é um tema anunciado como central advém, por vezes, de um assunto que não se encontra acessível, aparente. E, ao ser encontrado, é arrastado à superfície. É um processo de leitura emancipada, uma recepção recriadora do texto. É também possível que o tema esteja no próprio grupo, nas situações vivenciadas. No diálogo do grupo o tema recorrente que sinaliza as situações limites, os desafios, o lugar e as lutas sociais, sinaliza um ato político, democrático. É o tema gerador (FREIRE, 1993) expressão de desejos e meio de vida de um grupo, uma potência política que acentua as contradições sociais, e acontece na 
prática dialógica, da experiência existencial com reflexões críticas na relação da pessoapessoa e da pessoa-mundo.

Para Nickel (2009) ao abordar as dimensões do tema numa experiência da Pedagogia, a micro-dimensão compreende a esfera individual, ou seja, cada jogador traz em si uma origem, uma história. E cada um, individualmente, tem um desejo no passado e tem desejos para o futuro. Quem é a jogadora? De onde é? O que faz? O que gosta? O que não gosta? Quais os desejos? Quais os medos?

As dimensões do tema, na abordagem de Nickel, reportam, por aproximação, a temática significativa/universal no pensamento do educador Paulo Freire (1993). Uma temática trazida ao conhecimento de todos por meio de uma práxis dialógica. Busca-se um universo mínimo temático, um tema gerador que possibilite ao grupo perceber as situaçõeslimites e o desprendimento para a ação, para o expressivo, para um entendimento possível da realidade e das ações transformadoras para alcançar o "inédito-viável".

Contudo, as experiências coletivas que agregavam as marcas da individualidade, remetem à segunda dimensão proposta por Nickel (2009), a qual implica no entendimento do grupo situando a sua origem e o seu entorno, quer dizer, o grupo pertence a um determinado espaço, e, está imerso em um contexto. Na dimensão-mediana é assimilada a temática do espaço ao vivenciá-lo. Esta dimensão não deixa de refletir a micro-dimensão, pois o grupo é formado por indivíduos, portanto, reflexo do tema micro-dimensional. Nickel acentua a necessidade de saber se o grupo tem consciência dos temas trabalhados ou se a representação é uma construção aleatória.

Por fim, a terceira dimensão abrange os temas históricos. Aqueles temas que põem a sociedade como objeto de indagações. O que quer a sociedade? Aonde vai? Quais as perspectivas futuras da sociedade? Qual relação se pretende ter com os espectadores? Quais são os desafios que enfrentamos nesse tempo de distanciamento? Em tempo de pandemia, os temas de corpo e movimento entram em redimensionamento e apresentam novas indagações do presencial.

Os textos teatrais, em forma de poesia ou contos, não são, em geral, monotemáticos. No entanto, muitas vezes, identifica-se um tema entre outros no texto que se relaciona melhor com o interesse do grupo.

Neste caso, quando se define um tema para ser trabalhado, com frequência, esse processo tem uma finalidade que é a produção cênica. Na cena, o tema é parte do conteúdo que se torna objeto de apreciação e de interpretação dos espectadores. Neste sentido, no enquadramento do tema no processo criativo, Hans-Wolfgang Nickel (2009) apresenta Revista Interinstitucional Artes de Educar. Rio de Janeiro, V. 7, N. 1 - pág. 447-466 janeiroabril de 2021: "Pedagogias Vitais: Corpo, Desejo e Educação" DOI: 10.12957/riae.2021.54952 


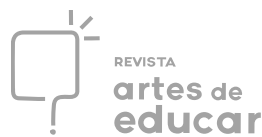

variadas formas de trabalhar com o tema: a partir de uma história, de um verbete, de um acontecimento, de uma sequência de cenas, um texto, um objeto, um espetáculo de dança, de uma peça teatral. Composições que formam a obra (Texto) com o seu conteúdo que necessariamente não precisam ser verbais. O grupo pode interpretar um tema (Texto) de várias maneiras: através de imagens, gestos, construções dos requisitos, figurinos, entre tantas outras variações de jogos com referências às obras compostas fora do contexto do grupo. $\mathrm{O}$ processo criativo, neste caso, dá-se na atividade de interpretação do material pesquisado.

O tema, como um referencial para improvisação, desencadeador do pensamento, de impulso para o jogo, do movimento e do canevas, não deixa de ser um texto, se o texto dramático não é mais, no século XXI, condição sine qua non para a cena (LEHMAN ${ }^{x v i i i}$, 2008; RYNGAERT, 1995).

\section{Corpo e movimento}

Selecionamos, em meio a outras referências utilizadas nas pesquisas em sala de aula, dois autores que compreendem o tema em seus modos distintos de acontecimento nas ações corporais educativas: Augusto Boal, com o teatro-imagem, e Laban com a dança educativa. Vê-se que os dois autores citados têm no tema uma passagem significativa. O movimento cotidiano, o movimento como libertação, conhecimento corporal e expressão temática seja na fluência criativa dos temas do movimento em Laban, seja na expressão de um mundo e dos desejos oprimidos em Boal, ambos constituem campos de experiências corporais com temas. Laban, na dança, e Boal, no teatro.

Em Rudolf von Laban (1978), o movimento espontâneo e cotidiano é pensado por um método criativo que visa a qualidade do movimento: peso, tempo, espaço e fluência. Em particular, são exercícios individuais e coletivos orientados por movimentos que trazem a consciência e o domínio corporal fora dos padrões até então, no século XIX, indicados pelos movimentos ginásticos. Todos podem encontrar a sua própria dança nos movimentos individuais e coletivos a partir das indicações dos temas de movimento e das ações básicas de esforço. No primeiro momento essa referência proporcionou a conexão com o teatro-imagem, sistematizado por Augusto Boal (1980), como uma das modalidades do Teatro do Oprimido. Assim como a dança educativa, o Teatro do Oprimido pode ser realizado por todos, por ser arte potencialmente humana. 
O teatro-imagem, que consiste em formas de comunicação sem o uso da oralidade, centrado apenas nas imagens produzidas corporalmente, são imagens surgidas de temas geradores priorizados como temas de interesses pelos estudantes em sala de aula. Os exercícios de teatro-imagem são técnicas propostas por Augusto Boal (1980; 1977), no livro Stop: c'est magique. Uma concepção de imagem corporal que se pretende libertadora.

Quando os oprimidos constroem suas imagens da realidade, o corpo externa formas de opressões culturalmente internalizadas cuja imagem vem à superfície por meio da comunicação corporal. Ou seja, expressão subjetiva como introjeção cultural e histórica. Boal (1980) se aproxima do pensamento de Vygotsky ${ }^{x i x}$ (1991) ao perceber que as opressões são de caráter psicológico e social e as imagens são consequências das ações mediadoras. Segundo Medina (1987, p. 68), "É preciso superar a visão do corpo como um simples objeto, um utensílio cuja preocupação básica é o rendimento e a produtividade tecida pelo lucro". Nesse meandro, as subjetividades como produtos dos modelos dominantes ou como construções críticas opositoras desses modelos tornam-se temas, imagens individuais que são transformadas pela ação dos espectadores. O teatro-imagem é a linguagem corporal em plena comunicação, experiência na qual a palavra expressada oralmente é evitada.

O teatro-imagem abarca jogos e exercícios que, mesmo tratando de temas sociais, tendem a despontar nas situações complexas das opressões interiorizadas, reafirmando o caráter psicossocial da ação. Boal deixa claros a finalidade e objetivo de seus exercícios. Com suas palavras: "Estamos habituados a olhar imagens que não nos deixam ver outras imagens, as quais poderiam passar diferentes informações. O objetivo dos exercícios é o de nos ajudar a ver aquilo que olhamos" (BOAL, 1980). Podemos perceber que, para Boal, há uma diferença entre olhar e ver, e são os exercícios do teatro-imagem que vão auxiliar nesse vínculo entre o ver e o olhar. Existe pelo menos três exercícios principais que nos ajudam a compreender como se dá o ver a partir daquilo que olhamos: a técnica do espelho, a modelagem e a marionete.

Tanto o teatro-imagem, como os movimentos espontâneos, com base nos temas cotidianos, apresentam-se como propostas de exercícios e jogos corporais criativos que ampliam as discussões acerca do corpo, movimento e ludicidade. As duas metodologias de dinâmicas corporais têm contribuído com os processos de ensino e aprendizagem de maneira crítica e reflexiva. 


\section{Discussão e considerações}

A disposição de um professor pesquisador põe em questão, a priori, a dicotomia existente entre teoria e prática. Quando se diz "sala de aula e subjetividades nas aulas de corpo, movimento e ludicidade" subjaz um espaço laboral, a sala de aula enquanto laboratório de encontros, de experiências corporais, de movimentos desafiadores e de fluência criativa, lúdica. As leituras de autores como Boal e Laban, entre outros, e os debates que fluem como alongamentos dos temas estudados escapam do plano retórico e tomam forma de ações corporais. Contudo, é perceptível que os livros estudados são escrituras de experiências, descrições, comentários e reflexões das ações.

No decorrer dos exercícios e jogos, durante as aulas, percebem-se as singularidades do grupo de estudantes ao atuar com as técnicas propostas pelos dois autores citados anteriormente. Todavia, os comentários da prática e as correlações com o material lido iam suscitando novas escritas por meio de protocolos e cartas.

O protocolo, longe de ser um formulário, um documento sem marcas, sem traços de subjetividade aparente, é uma escrita que deixa as pegadas de quem descreve e comenta sobre o desdobramento do componente curricular Corpo, movimento e ludicidade, as questões inerentes à sala de aula como espaço de subjetividades exigem as mais diversas abordagens em contraposição à “objetividade" positivista, sem, no entanto, desvanecer no espontaneísmo.

Verifica-se, ao se tratar do corpo e movimento, a perpetuação da concepção de corpo, na Educação, ainda com resquícios do movimento ginástico europeu, surgido no século XIX, do corpo higienizado, das práticas de fitness e wellness na busca pelo corpo saudável, do bem estar e da qualidade de vida (DANTAS, 2005). O corpo entendido como realidade "biopolítica", como objeto modelado pelo poder, como movimento controlado coercitivamente pela sociedade. Ao que parece são movimentos dados no espaço formal, não formal e informal. Sendo o último espaço, lugar subjetivo, aonde a objetividade não vai além das regras do jogo proposto, embora, efetivamente, mobilize-se o jogo como alongamento da cultura e da história.

Digamos que o corpo aqui tratado se encontra no espaço formal do estudo teórico e da prática em sala de aula como experimento do conteúdo estudado. Por isso a necessidade da escrita dos protocolos e das análises e reflexões sobre as atividades desenvolvidas no decorrer das aulas. Só assim, documentos de registro foram produzidos para, posteriormente, subsidiarem as pesquisas e as reflexões sobre as atuações em sala de aula. 
Nos protocolos e cartas dos estudantes fica acentuado o trabalho com o corpo como atividade significativa. Os estudantes falam da necessidade de sentir o corpo, de relaxar, de exercitar os sentidos. Alguns estudantes veem as dinâmicas do teatro-imagem e dos movimentos de Laban como "[...] um momento para conhecer o nosso corpo, onde na correria do dia a dia esquecemos dele e de nós mesmos" (Estudante A). Ou seja, o corpo é um lugar esquecido, adormecido e a rotina cotidiana não nos deixa ser. Para a estudante B, com referência ao teatro-imagem: "Construímos, recriamos, mudamos a percepção ao olharmos para uma imagem com olhar de libertador." Nesta frase espera-se pela "liberdade" para transformação da imagem.

Assim, a pesquisa prossegue intermediando os protocolos e as cartas no intuito de verificar como os temas são assimilados pelos estudantes, e qual é o desdobramento do movimento corporal associado às metodologias do movimento em Laban e do teatro-imagem.

Todavia, a caminho da guisa de conclusão, o corpo ocupa o espaço e se mostra como ressonância do corpo social. Como parte de uma dada cultura, ele já indica e diz o que é e como está inserido contextualmente, ou se apresenta como mera reprodução das relações sociais, do que se cultiva como costumes, ou se expressa de forma reativa aos modos de ser do seu próprio meio. Ao ocupar o espaço, torna-se espaço, um lugar vigiado pelo controle social. Desde o nascimento, o corpo é marcado, tocado pelos adultos, e nele impresso os signos culturais correspondentes à conduta social e psicológica esperada por um grupo específico.

Para Marques $^{\mathrm{xx}}$ (2010), o corpo delicado, o movimento suave, numa sociedade machista, é um modo de ser e se movimentar das mulheres, o que não cabe ou não é aceitável aos homens. "São nossos corpos que primeiramente indicam a qual etnia pertencemos (cor da pele, estrutura óssea, formato dos olhos, da boca do nariz)". Esta mesma autora consegue trazer, sucintamente, a valoração do corpo no espaço escolar quando acentua a importância da dança:

A linguagem da dança é uma área privilegiada para que possamos trabalhar, discutir e problematizar a pluralidade cultural em nossa sociedade. Em primeiro lugar, o corpo em si já é expressão da pluralidade. Tanto os biótipos encontrados hoje no Brasil quanto a maneira com que esses corpos se movimentam, tornam evidentes aspectos sócio-políticos-culturais nos processos de criação em dança. (MARQUES, 2010, p. 37)

Apesar de o corpo ser, à primeira vista, o que se apresenta, a carapaça o reafirma como lugar onde tabus, medos, credos, punições, explorações, entre tantos outros substantivos, 
alojam-se na condição de invasores provocadores de bloqueios dos gestos e dos movimentos. Convive-se com delimitações dos movimentos no julgamento de alguns gestos que são tidos como exclusivos do feminino, outros do masculino e outros dos homossexuais (MARQUES, 2010).

Não duvidamos de que a sala de aula seja um espaço de encontros, uma vez que o cotidiano se manifesta com suas variações, tecendo a dinâmica das aulas na ampliação do tema e das expressividades corporais singulares. Partindo desse pressuposto a ideia que se tem de corpo e movimento atinge os mais diversos entendimentos implicados nas crenças e valores, nos quais o corpo é lembrado e conhecido ou relegado ao esquecimento, parte desconhecida e intocável, como se fosse possível a separação corpo e mente.

O nosso desafio tem sido encontrar nos autores citados formas possíveis de realizar movimentos individuais nos espaços das residências, observando os temas de movimento de Rudolf von Laban intercalando com outros exercícios realizados a distância e unidos por meio das imagens digitais filmadas ou em tempo real. Danças que além de explorarem os temas de movimentos em Laban, também sugerem temas do cotidiano: como zona rural, cidade, indústria, cotidiano, trabalho, solidão, bullying, violência.

Com a técnica do teatro-imagem, é possível pensar e fazer acontecer imagens que representam situações de opressões fazendo uso de máquina fotográfica. Essas imagens são apresentadas em sala de aula e, com elas, realizadas atividades descritivas que motivam múltiplos debates do que as imagens reportam com vista às opressões que representam. Essas práticas experimentais possibilitam as correlações entre teoria e prática, sobretudo quando discutir movimento e ludicidade ascende à experiência, aos sentidos, ao campo do sensível.

\section{REFERÊNCIAS}

BOAL, Augusto. Técnicas Latino-Americanas de Teatro Popular. São Paulo: Hucitec, 1977.

. Stop c'est magique! Rio de Janeiro: Editora Civilização Brasileira, 1980.

DANTAS, Estélio H. M. Pensando o Corpo e o Movimento. Rio de Janeiro: Shape, 2005.

FREIRE, Paulo. Pedagogia do oprimido. São Paulo: Paz e terra, 1993.

LABAN, Rudolf. O Domínio do Movimento. $3^{\mathrm{a}}$ ed. Tradução Anna Maria Barros de Becchi; Maria Silvia Mourão Netto. São Paulo: Summus, 1978. 
LEHMANN, Hans-Thies. O Teatro Pós-Dramático. Trad. Pedro Sussekind. São Paulo, Cosac\&Naify, 2007.

LIBÂNEO, José Carlos. Tendências pedagógicas na prática escolar. In:

Democratização da Escola Pública - a Pedagogia crítico-social dos conteúdos. São Paulo: Loyola, 1992. <http://www.ebah.com.br/content/ABAAAehikAH/libaneo>. Acesso em 20/julho/2020.

LIMA, H. J.R. O tema no processo criativo das asmarias cia de teatro. Dissertação de mestrado, Natal RN, 2011.

MARQUES, Isabel A. Dançando na escola. 5a . ed. São Paulo: Cortez, 2010.

MEDINA, João Paulo Subirá. O brasileiro e seu corpo: educação e política do corpo. 2. ed. Campinas, SP: Papirus, 1990.

NICKEL, Hans-Wolfgang. Regie: Thema und Konzept. Berlim, Schibri-Vorlag, 2009.

NISTA-PICCOLO, Vilma L; MOREIRA, Wagner W. Corpo em movimento na Educação Infantil. São Paulo: Cortez, 2012.

PAVIS, Patrice. Dicionário do teatro. SP: Perspectiva, 2005.

RANCIÈRE, Jacques. O inconsciente estético. São Paulo: Ed.34, 2009.

ROMERO, Elaine. Do Corpo Docilizado na Aufkllärung ao Corpo Generificado no Século XXI, In: DANTAS, Estélio. Pensando o corpo e o Movimento. $2^{\text {a }}$ ed.Rio de Janeiro: Shape, 2005. p. 34-94.

RYNGAERT J. J. Introdução à análise do teatro. Trad. Paulo Neves. São Paulo, Martins Fontes, 1995.

SANTIN, Vinicius. Visão Lúdica do Corpo. In: DANTAS, Estélio. Pensando o corpo e o Movimento. 2 ed. Rio de Janeiro: Shape, 2005. p. 309-320.

SCARPATO, Marta Thiago. O corpo cria, descobre e dança com Laban e Freinet. Campinas, SP, 1999.

VYGOTSKI L.S.A formação social da mente. São Paulo: Martins Fontes, 1991.

\footnotetext{
${ }^{\text {i }}$ Doutor em Estudos da Linguagem (UFRN), mestre em Artes Cênicas (UFRN) especializado em Pedagogia do Teatro e coordenação de jogos com fundamentação pedagógica pela Theaterpädagogische Akademie BuT Bundesverband Theaterpädagogik e. V., Heidelberg/Alemanha e graduado em Pedagogia (UERN). Tem experiência na educação formal e não-formal, no litoral e no campo, atuando com crianças, adolescentes, adultos e idosos. Discute aspectos de processos criativos de leitura e escrita através do texto dramático, de jogos e exercícios teatrais atravessados por teorias instigadoras de ações emancipadas (Augusto Boal) e de redistribuição da ordem do sensível (Rancière) associadas ao plano de pensamento de Deleuze e Guatarri no que tange aos Revista Interinstitucional Artes de Educar. Rio de Janeiro, V. 7, N. 1 - pág. 447-466 janeiroabril de 2021: "Pedagogias Vitais: Corpo, Desejo e Educação" DOI: 10.12957/riae.2021.54952
} 
planos territoriais, as desterritorializações e reterritorializações como desdobramentos políticos da pedagogia e da arte. Atualmente é professor adjunto da Universidade do Estado do Rio Grande do Norte UERN e do Programa de Pós-Graduação em Educação POSEDUC, atuando na área de corporeidade e ensino de arte, com interesse na linha de pesquisa: práticas educativas, cultura, diversidade e inclusão. Instituição/Afiliação: Universidade do Estado do Rio Grande do Norte/RN. Brasil. ORCID iD https://orcid.org/0000-0003-4353-7003

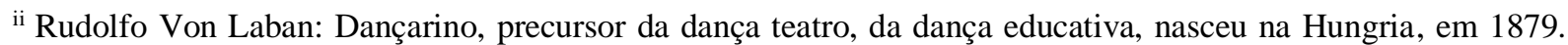
Compreende a pessoa como dançarina em potencial, cada um pode dançar a sua dança. Apresentando os elementos do movimento, Laban sistematiza um método no qual a improvisação e a espontaneidade são imprescindíveis na execução da partitura dos movimentos propostos.

iii Augusto Boal: Ensaísta, cronista, dramaturgo, diretor de teatro, pedagogo do teatro e sistematizador do Teatro do Oprimido, modo de fazer e pensar o teatro com a participação do espectador na área de atuação. Nasceu no Rio de Janeiro, em 1931.

iv João Paulo Subirá Medina: Atua na área de Educação Física, é autor e co-autor de diversos livros nas áreas da Educação Física, saúde e psicologia. O livro O brasileiro e seu corpo: educação e política do corpo tem propiciado discussões e reflexões sobre o corpo dos brasileiros.

v José Carlos Libâneo: Educador e escritor brasileiro. Estudar as tendências pedagógicas a partir dos escritos de Libâneo, leva-nos às abordagens que desejamos na educação ao trazer como metodologias os movimentos de Laban e o teatro do oprimido de Augusto Boal. Busca-se conexões ao longo dos estudos e dinâmicas em sala de aula, na construção epistemológica do corpo, do movimento e da arte na educação das pessoas.

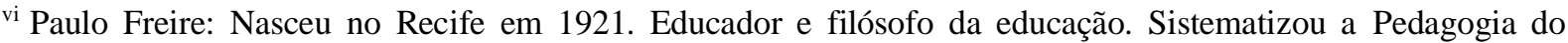
Oprimido. Crítico da educação bancária, propõe uma educação libertadora em que todas as pessoas possam ter acesso e exerçam a cidadania.

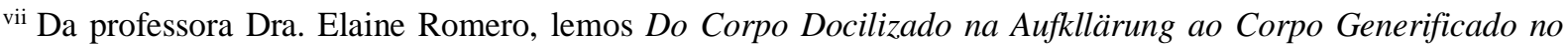
Século XXI, uma perspectiva histórica e filosófica do corpo. Esse estudo é um capítulo do livro de Estélio Dantas Professor da Universidade Federal do Estado do Rio de Janeiro. Progr. Pós-grad Stricto Sensu em Enfermagem e Biociências. O livro Pensando o corpo e o Movimento nos ajuda a pensar sobre o conceito de corpo docilizado.

viii Professor do Mestrado em Educação Física da Universidade Federal do Rio Grande do Sul, traz a visão lúdica do corpo no seu artigo que compõe o livro de Esteio Dantas "Pensando o corpo e o movimento".

ix Marta Thiago Scarpato: "O corpo cria, descobre e dança com Laban e Freinet", esta dissertação, de certo modo, amplia a nossa perspectiva no trato da dança, do movimento e os processos pedagógicos da escola.

x Vilma Lení Nista-Piccolo: Professora no programa de pós-graduação em educação da universidade de Sorocaba. Pesquisa a Corporeidade na escola. A sua pesquisa possibilita estudos desafiadores no entendimento do movimento na escola; e, Wagner Wey Moreira: Professor da Universidade Federal do Triângulo Mineiro, tem interesse na área de Corporeidade e Pedagogia do Movimento na Cultura e pesquisa a educação e o corpo criança na fase inicial do Ensino Fundamental no Brasil e ensino básico em Moçambique.

xi Psicólogo francês do século passado.

xii Jacques Rancière: Filósofo francês. Seu trabalho concentra-se na área da estética e da política. De Rancière trazemos reflexões para pensarmos o tema, embora trate de exemplo sobretudo do texto dramático, pensamos o tema enquanto assunto, sujeito no processo de criação do movimento o da imagem corporal.

xiii Hélio Rocha de Lima: Pedagogo do teatro e professor. Pesquisa o tema no processo criativo do movimento, da imagem corporal, temas geradores em processos da Pedagogia e da arte.

xiv Tema fundamental e figura de repetição. - "De modo mais geral, toda retomada de termos, toda assonância, toda conversa que gira em torno de si mesma (TCHÉKHOV) constitui um leimotiv" (PAVIS, 2007, p. 227)

${ }^{x v}$ Constantin Stanislavski: Ator, diretor, pedagogo e escritor Russo.

${ }^{\text {xvi }}$ Patrice Pavis: Professor de teatro. Pesquisador da performance. Usamos o dicionário do teatro. Os estudos de Pavis provocam inquietações sobre a escrita dramática e da cena, de modo a trazer um olhar sobre os processos da escritura dramática contemporânea.

${ }^{\text {xvii } H a n s-W o l f g a n g ~ N i c k e l: ~ P r o f e s s o r ~ d a ~ U d K ~ U n i v e r s i d a d e ~ d e ~ A r t e ~ d e ~ B e r l i n . ~ A ́ r e a ~ d e ~ c o n c e n t r a c ̧ a ̃ o: ~ J o g o ~}$ dramático. teatro na escola e Pedagogia do teatro. Neste artigo nos debruçamos sobre a pesquisa de Nickel acerca do tema e concepções no processo de encenação.

Revista Interinstitucional Artes de Educar. Rio de Janeiro, V. 7, N. 1 - pág. 447-466 janeiroabril de 2021: "Pedagogias Vitais: Corpo, Desejo e Educação" DOI: 10.12957/riae.2021.54952 
xviii Hans-Thies Lehmann: É crítico e professor de teatro alemão, criador da obra "Teatro Pós-dramático". Para Lehmann, uma vez que o texto não é mais a base de uma dramaturgia, o tema pode desdobrar-se em jogo cênico. Citamos este autor pelo fato de, juntamente com Jean-Pierre Ryngaert, abrir possibilidades improvisacionais no trato criativo do tema como dinâmicas contemporâneas das Artes cênicas e da Pedagogia do teatro.

xix Vygotski: Dada a importância para a Pedagogia e para a arte, o autor estudado elucida suas questões através de exemplos dramatúrgicos. Seu interesse pelo teatro, além da abordagem histórico-cultural une e amplia perspectivas no que compreende a educação e a arte como acontecimentos híbridos de aprendizagens.

${ }^{\mathrm{xx}}$ Isabel Marques : Pedagoga e professora de dança. O fato de ter contribuído com as propostas curriculares nacionais, contribui para o entendimento da dança educativa na escola, na sala de aula, além de tecer discussão acerca da Pedagogia e da arte. 